\title{
Good things come in small packages: is there a common set of motivators for energy behaviour?
}

\author{
Britt Stikvoort • Peter Juslin • Cajsa Bartusch
}

Received: 1 December 2016 / Accepted: 11 June 2017 /Published online: 4 July 2017

(C) The Author(s) 2017. This article is an open access publication

\begin{abstract}
Household energy consumption can be curbed by individuals' energy saving, yet despite many efforts, our energy consumption is not lowering. This study investigated the role of a common set of behavioural determinants for households' intention to perform four energy-related behaviours: investing in PV cells, turning off apparatus on standby mode, showering less, and replacing old home appliances with new energyefficient ones. Behavioural determinants-energy awareness, general energy knowledge, attitudes, subjective norms, perceived behavioural control, and moral norms - were assessed in a survey $(N=83)$ among Swedish residents. Energy awareness was moderately correlated with energy knowledge, but not with respondents' intentions to perform the behaviours, except for replacing home appliances. Moral norms were judged by respondents as important motivators and were a strong predictor to behavioural intentions to perform all four behaviours. Attitudes likewise were assessed as important motivators and were important predictors to all behavioural intentions except investing in PV cells, which was instead predicted by perceived behavioural control. Respondents' assessment of beliefs underlying attitudes also differed for investing in PV cells; namely, beliefs about economic benefits were lower.
\end{abstract}

B. Stikvoort $(\bowtie) \cdot$ P. Juslin

Department of Psychology, Uppsala University, Von Kraemers allé 1A-C, Uppsala, Sweden

e-mail: britt.stikvoort@psyk.uu.se

C. Bartusch

Department of Engineering Sciences, Ångströmlaboratoriet, Uppsala University, Lägerhyddsvägen 1, Uppsala, Sweden
Moreover, respondents felt less morally responsible for investing in PV cells. Concluding, we found no evidence that intentions to engage in four energy-saving behaviours are mediated by general energy knowledge or energy awareness. Determinants to each behaviour differed, where - surprisingly — investment in PV cells stood out as less motivated both by economic incentives and moral concerns, although moral norms were shared motivators across all four behaviours. We discuss different possible interpretations of these findings.

Keywords Social psychology · Energy saving · Energy awareness $\cdot$ Behavioural determinants $\cdot$ Survey

\section{Introduction}

The world's current energy usage is unsustainable and problematic (Hirschnitz-Garbers et al. 2016), and the need for households to reduce their energy consumption and shift towards renewable sources is fairly wellknown among lay people (Reynolds et al. 2010). With fossil fuel being the most common source of energy generation, current society's need for it contributes to climate change and other environmental issues (Dincer 2000). Part of the responsibility for this lies with households, as considerable end users of this energy [e.g. about $24 \%$ of the final energy consumption of EU-28 countries comes from the residential sector (Eurostat 2016)]. Without losing significant quality of life or comfort, households could reduce domestic energy use by up to 20\% (Dietz et al. 2009; Lopes et al. 2012) but 
instead, we see a rise in household energy consumption (Eurostat 2016). In short, domestic energy use can and should change, but it does not. Why not? In this study, we investigated psychological motivations for four dissimilar domestic energy behaviours. We looked at factors that could explain an individual's engagement in these behaviours, and what (dis)similarities there are in these motivating factors to behaviour.

Many governmental institutions and non-profit organizations, as well as companies, have tried to change people's behaviours for the sake of social (environmental) goods, and research has often been used to test and evaluate interventions aimed at helping people act right. Also, in the field of energy conservation, this holds true; an abundance of literature describes interventions designed to curb people's energy consumption, or change it to more renewable practices (Kallbekken et al. 2013; Pichert and Katsikopoulos 2008; Schultz et al. 2007). Many of these interventions are based on behaviour models, which describe so-called determinants to behaviour, or factors that influence behaviour. The underlying assumption is that behaviour change will occur in the direction that the aggregate of determinants points towards. Since behaviour is complex, no single determinant has been unequivocally linked to behaviour, and it is in combination that behavioural determinants start to make sense of an individual's behaviour. In behaviour models, then, important determinants are put together in such ways as to make sense of people's acts and decisions.

A range of studies focus on determinants and models' relation to specific energy-related behaviours (for example, concerning commuting choice: Bamberg and Schmidt 2003; recycling: Chan and Bishop 2013; car use: Wall et al. 2007) or to aggregates of multiple behaviours together (for example, a meta-analysis by Klöckner 2013a). We wondered whether some determinants to behaviour are involved in (nearly) all behaviours, and to what extent these contribute differently or similarly across behaviours. Note that we are not excluding the possibility that there are some unique determinants that contribute only to one or a few behaviours. Rather, we are interested in finding determinants that have a say in a broad range of behaviours related to energy consumption. Instead of aggregating behavioural reports together and testing determinants on this aggregate (as was done excellently by Klöckner 2013a), we aim to directly compare determinant-behaviour relationships for behaviours. The specific aim of this current survey study was thus to investigate the (dis)similarity of the role of a specific set of determinants (defined later on) when looking at different energy behaviours: investing in solar panels, turning off appliances that are on standby, reducing the time spent showering and replacing old household appliances with new energyefficient ones. We will discuss the choice of these behaviours in a later section, but first mention a phenomenon that is related to the idea that behaviours share a common set of determinants: potential spillover effects.

Spillover effects occur when an intervention (or behaviour) has an effect on subsequent behaviours not targeted by the intervention (Truelove et al. 2014). A practical example is the increase of energy consumption in a sample of households who reduced their water consumption following a water reduction campaign (Tiefenbeck et al. 2013). Note that this is a negative spillover effect, where increase in one behaviour denotes decrease in another. Positive spillover effects have also been identified (see Truelove et al. 2014 for examples).

Some authors have suggested that awareness of environmental issues can be a mechanism behind environmental spillover effects, with one behaviour affecting other behaviours via means of a raised awareness (Tiefenbeck et al. 2013). But the debate on mechanisms behind spillover effects is still open. Although the current study cannot warrant causal conclusions, we suggest that finding determinants that are shared among multiple energy behaviours can tentatively point towards possible mechanisms for spillover effects; in other words, if it is found that one determinant is common for behaviours $\mathrm{A}$ and $\mathrm{B}$, raising this determinant by means of an intervention, in order to induce behaviour A, may also induce behaviour B.

\section{Theoretical background}

In this section, we describe the theoretical background underlying the determinants that we investigated. Given the scope of the study, we did not encompass all theoretically possible determinants, but rather selected determinants based on their origin in the individual (i.e. not a structural or physical push or pull, or social practices), their pervasiveness in the literature on proenvironmental behaviour and their resonance with a pilot run prior to the survey (more on this in the next section). We would like to point to Nair et al. (2010) for a distinction between personal and contextual (structural) factors, and to Gram-Hanssen (2010), Shove 
(2010), Sovacool (2009) and Wallenborn and Wilhite (2014) for work focusing on social practice or cultural aspects of our behaviours.

A common assumption in many environmental campaigns is that people somehow lack knowledge or awareness of the problem or solutions needed for behaviour change (Kollmuss and Agyeman 2002). Most contemporary intervention researchers acknowledge that there are many factors that affect behaviour, for example, social norms (Schultz et al. 2007), contextual factors (Nair et al. 2010) or awareness of one's own consumption (Brounen et al. 2013). In this study, we combine awareness and knowledge with constructs from frequently used psychological behaviour models. Below, we first address awareness and knowledge and thereafter discuss constructs from two behaviour models, the theory of planned behaviour (TPB: Ajzen 1991) and norm activation theory (NAT: Schwartz 1977), both of which have been successfully applied in the pro-environmental behaviour context.

Awareness and knowledge

Despite the multifaceted nature of determinants to behaviour, many pro-environmental intervention campaigns still rely in some way or another on knowledge and problem awareness (Kollmuss and Agyeman 2002; Steg and Vlek 2009). A recent meta-analysis found that information strategies for energy-saving behaviour had indeed been effective to some extent, though much depended on the method of informing respondents (Delmas et al. 2013). About 7\% energy reduction could be attributed to interventions using information (which incorporated information containing peer comparisons), though this score dropped significantly when only highquality papers were analysed (approx. 2\%: Delmas et al. 2013). As mentioned earlier, about $20 \%$ energy reduction could be feasible without significant loss of household well-being (Dietz et al. 2009), ${ }^{1}$ suggesting that information interventions may not be sufficient. But in order to know what other factors to look out for, we need to define exactly what is entailed by 'awareness' and 'knowledge'.

The concept of awareness can be defined in various ways. Awareness of consequences of one's own actions for instance is used in the norm activation theory to explain pro-social behaviour (Abrahamse and Steg

\footnotetext{
${ }^{1}$ This study focused on the situation in the USA
}

2009). Others defined energy awareness as people's awareness of their own energy consumption (Brounen et al. 2013) rather than on the consequences of energy behaviour. A third kind of awareness is that towards environmental consequences (Gärling et al. 2003), which focuses on only consequences of actions that impact the environment.

In this study, we focus on awareness of one's own energy consumption, which seems a likely candidate determinant to the change of energy behaviour. Common sense reasoning would suggest that someone needs to know that his or her needs and wants can be achieved with less energy and hence that his/her energy consumption is higher than necessary, before he or she can actively engage in energy-saving activities. Hence, awareness of energy consumption is (at face value) an important determinant to energy saving. Such awareness of one's energy consumption can easily emerge from currently 'trending' movements such as providing personal feedback or implementing smart in-home electricity meters, and as such, awareness is a plausible candidate for being a carrier of spillover effects from energysaving campaigns to other behaviour, which is another reason for paying attention to this determinant. ${ }^{2}$ As is investigated in Delmas and colleagues' meta-analysis (Delmas et al. 2013), information can occur in many shapes and sizes, and each strategy has varying degrees of success.

What, then, about knowledge? There is an increased interest in so-called energy literacy, which is often considered to contain (or be equal to) factual knowledge about energy, although there is no universally agreed upon definition. For example, DeWaters and Powers (2011) designed a survey for American high school students, measuring energy literacy that contained factual, affective and behavioural aspects. Brounen et al. (2013) on the other hand used questions like 'what is your monthly gas bill' and 'have you used an energy label for your home during the last three years?' as indicators of energy literacy. The latter interpretation of energy literacy fits more with our definition of awareness of one's energy consumption. To cover purely the factual knowledge aspect of energy literacy, we focused on respondents' levels of information on energy

\footnotetext{
${ }^{2}$ Note that survey respondents were aware that the data would be handled anonymously and answered in their own private spheres, which should minimize the effect of responding with socially desirable answers.
} 
consumption and production in Sweden and their knowledge on what strategies are best to save energy in-home. With these definitions of awareness and knowledge, we now turn to the constructs from behaviour models.

\section{Theory of planned behaviour}

The theory of planned behaviour focuses on how behaviour is predicted by intentions to perform that behaviour. Intentions are in turn predicted by attitudes towards the behaviour, subjective norms and perceived behaviour control (Ajzen 1991). The latter is assumed to feed back into intention and directly into behaviour (Ajzen 1991). Although the theory predicts behaviour from intentions (and actual behavioural barriers), one further requirement for the model to be useful is volitional control over the behaviour (Ajzen 1991), which is the case in the energy behaviours central to this study. In other words, respondents must have an actual capacity to influence their behaviour and the belief that they can.

The TPB is based on an expectancy-value model approach, where attitudes, subjective norms and perceived behaviour control (henceforth referred to as PBC) are assumed to consist of a product of beliefs we hold. Thus, attitudes, subjective norms and PBC arise from beliefs about behaviour and the subjective strength of these beliefs. Studying motivations at the belief level accordingly reveals more detailed accounts of why people perform a certain behaviour (or why not). Beliefs for one's attitude are about positive or negative aspects of a behaviour (e.g. investing in solar panels is economically beneficial for my household). Each belief can be held strongly or less so, with the resulting attitude of a person being a product of his/her beliefs times the strength or importance at which he/she holds these beliefs. A similar structure is proposed for beliefs underlying subjective norms, beliefs about what important people in one's vicinity think of the behaviour and again, the strength of such beliefs. For PBC, the theory proposes beliefs concerning the presence of resources or opportunities and the absence of barriers. Again, PBC is a product of all control beliefs times their strength.

In his early work, Ajzen himself acknowledged that adding a construct he referred to as moral norms to the TPB could contribute to the predictions of intentions (Ajzen 1991). Yet, his conception of moral norms was never fully integrated into the TPB. Later, authors have criticized the theory for its lack of attention to moral norms (Klöckner and Blöbaum 2010). The norm activation theory instead focuses very much on moral norms, so we will discuss this theory next.

\section{The norm activation theory}

The NAT was proposed originally as explaining under which conditions people were likely to show pro-social and altruistic, that is, helping, behaviour (Schwartz 1977). Pro-environmental behaviour can be interpreted as a type of altruistic behaviour, since it often requires a person to give up personal benefits for the sake of the greater good (Abrahamse and Steg 2009). A moral (or personal) ${ }^{3}$ norm is a feeling of moral obligation, and performing this obligation can result in a feeling of pride, whereas neglecting said obligation can result in a feeling of guilt (Abrahamse and Steg 2009). Due to initial vagueness on the exact way in which constructs of the theory were related to one another, many different versions of the NAT currently exist (Klöckner 2013b), though central to most are the influence of moral norms on people's behaviour, the influence of awareness of consequences of their own behaviour and ascription of responsibility on moral norms (Abrahamse and Steg 2009).

It should be noted that the constructs from these two theories are sometimes integrated into one model (Abrahamse et al. 2007; Bamberg and Möser 2007; Bamberg and Schmidt 2003; Chan and Bishop 2013; Kaiser et al. 2005; Klöckner 2013a; Wall et al. 2007). Although many combinations of the two have been made, in this study, we adopted the main structure of the TPB with the addition of moral norms as an extra construct, in accordance with the approach of Harland and colleagues (Harland et al. 1999; Manstead 2000)

\section{Survey design}

In the following section, we describe a survey study that ran in the summer of 2016 among Swedish respondents $(N=83)$. This study was in fact a pilot for the final survey; the ultimate aim of the final product was to be a measurement tool capturing pre- and post-intervention changes in determinants of one target behaviour and

\footnotetext{
3 Personal and moral norms are used interchangeably in the literature on norm activation. We chose to talk about moral norms in this paper, but equate this with the term personal norm that is used in some other articles.
} 
various other behaviours. To make the survey applicable to many contexts, its design is modular: each behaviour can be replaced by another behaviour, and questions (gist) would remain the same. This modularity facilitates the future use of this survey with different behaviours, in accordance with the needs of the research at hand. Returning to the case at hand, here we used the survey to investigate four energy behaviours, ${ }^{4}$ namely:

1. Investing in photovoltaic (PV) panels (invest in PV)

2. Turning off apparatus from its standby mode (turn off standby)

3. Showering less long or frequent (shower less)

4. Replacing old household (home) appliances with new energy-efficient ones (replace appliances)

For each of the above mentioned behaviours, we measured the beliefs of the TPB constructs, respondents' sense of responsibility towards it and their intentions and self-reported behaviour. ${ }^{5}$ Energy awareness and knowledge about energy were measured once, because these constructs are focused on a general energy behaviour level. The constructs of the TPB, however, are best measured on the same level as the target behaviour (Ajzen 1991) which means that the beliefs for each behaviour must be measured for each behaviour separately. The specific beliefs for each behaviour were procured in an open-ended pre-pilot questionnaire, in which respondents listed anything that they considered to have influence on their performance of these four behaviours. All four behaviours had the following behavioural beliefs (forming attitudes) in common: economic benefits (determinants), environmental benefits

\footnotetext{
${ }^{4}$ These behaviours were selected as representations of the wide array of possible energy-related behaviours. We aimed to include behaviours with initially very high costs, for example, solar panel investment and replacement of household appliances to a lesser extent, and behaviours with zero monetary costs, e.g. turning off lights. Likewise, we included one-off choices, like solar panel investment, and behaviours that were of repeated daily nature, such as showering (less). Due to limited space, we contained the portfolio to just the four above-mentioned behaviours, though of course other behaviours could have been chosen instead.

${ }^{5}$ As discussed earlier, intentions (together with actual volitional control over behaviour) are suggested to lead to behaviour. In the survey, we attempted to capture behaviour with a self-report measure, but the measurement was unreliable and inaccurate, as is often the case for self-reports (Kormos and Gifford 2014), and we thus chose not to use it in the analyses. We focus instead on intentions towards behaviour in this study.
}

and gain (loss) of comfort or quality of life. ${ }^{6}$ Other beliefs were mentioned for two or less of the four behaviours; these were incorporated into the survey and used to calculate composite scores for attitudes and PBC. However, since they were not universal across the four behaviours, we cannot compare the effects of these beliefs across behaviours.

\section{Methods}

Respondents

The survey was administered during August 2016, using a convenience sample of the employees of a housing company in Uppsala, Sweden. Since it is difficult to obtain random email addresses from the Swedish population, which is the target population of this study, we instead ran the survey in a single company that has little direct links to environmental practices. Given that the company had no direct connections to such topics, employees can be considered to represent people from the Swedish (working) population. By making a link to the survey available to all members of the company via its intranet pages and rewarding participants with a cinema ticket, we aimed to reach respondents from all levels of the company. In total, 90 people commenced the survey, of which 83 responses were useful for further analysis (seven respondents opened the survey but never made it past the first page). The sample contained 43 women and $40 \mathrm{men}$; thus, responses were evenly distributed across gender. The sample was skewed towards highly educated respondents, with $52 \%$ reported to have at least completed university studies. The national average for completing this educational level is 40\% (SCB 2016). The sample had $37 \%$ respondents who stated secondary education as their highest completed form of education, for which the Swedish average is $45 \%$. Mean age of the sample was 37.1 years $(S D=11.9)$, which is lower than the national average of 41.2 years. The mean monthly income (self-reported) was 49,675 Swedish Kronor $(S D=19,241.4$, equivalents in euros are $M=5177$, $S D=2002.16$, with contemporary currency rates).

\footnotetext{
${ }^{6}$ For comfort/QoL, we asked respondents first to indicate whether they thought PV cells would have a detrimental or beneficial effect. Out of 72,66 respondents stated it would have a positive effect. For showering less and turning off standby, we assumed the belief to always be 'will negatively affect comfort levels' and for replacing household appliances the belief was always considered to be positive.
} 


\section{Procedure and measurements}

The survey was administered online via LimeSurvey, and respondents could complete it in stages, although of those who finished it completely, only one respondent made use of this option. It took about half an hour to complete $(M=36 \mathrm{~min})$. The survey consisted of several parts that were each presented on a separate page. After respondents agreed to participate, they answered on demographics, energy awareness and energy knowledge, respectively, on pages 1 to 3 . The fourth to seventh pages were each dedicated to one behaviour, probing after the relevant psychological constructs with the discussed measures in the succeeding sections. The final page consisted of a thank you.

\section{Awareness and knowledge of energy consumption}

Four questions probed people's awareness of their own energy consumption, as done in Brounen et al. (2013). We asked respondents if they knew their energy usage in terms of kilowatt-hours, the size of their energy bill in monetary terms and if they knew who their electricity retailer and distribution provider, respectively, were. ${ }^{7}$ Since we had no access to actual energy consumption, we could not verify numerical reports of respondents; we thus asked them only if they were aware of their consumption (and not to report this consumption). Table 1 shows English translations of the awareness questions along with the percentage of respondents responding positively to them. Reliability of a composite of these four questions was acceptable (Cronbach's $\alpha=0.752$ ), and no dramatic increase in reliability was detected after deleting items. The resulting composite 'awareness' had a mean score of $2.62(S D=1.36)$ where every 'yes' was coded as a 'one', thus creating a variable ranging from zero to four, with four indicating high awareness.

The knowledge questions on energy were focused on energy consumption and conservation. We incorporated three general questions on energy production on a nationwide basis, one question on 'average' household's consumptions and two very specific questions on appliance energy consumption (see Table 1). We aimed to have a set of questions that

\footnotetext{
${ }_{7}^{7}$ In Sweden, households get electricity from an energy provider, but this provider operates on an electricity grid that is owned by the distribution provider. Households pay fees to both.
}

Table 1 Energy consumption awareness and knowledge

\begin{tabular}{|c|c|}
\hline Awareness of energy consumption & $\begin{array}{l}\text { Percentage saying } \\
\text { 'yes' }(N=83)\end{array}$ \\
\hline $\begin{array}{l}\text { Do you know how much electricity your } \\
\text { household uses every month, in } \\
\text { kilowatt-hours? }\end{array}$ & 37 \\
\hline $\begin{array}{l}\text { Do you know (approximately) what your } \\
\text { household spends monthly on } \\
\text { electricity? }\end{array}$ & 69.1 \\
\hline $\begin{array}{l}\text { Do you know who your electricity } \\
\text { provider is? }\end{array}$ & 77.8 \\
\hline $\begin{array}{l}\text { Do you know which company owns the } \\
\text { electricity grid that your house is } \\
\text { connected to? }\end{array}$ & 77.8 \\
\hline Knowledge of energy consumptions & $\begin{array}{l}\text { Item difficulty } \\
(N=83)(\% \\
\text { correct })\end{array}$ \\
\hline \multicolumn{2}{|l|}{ Energy in Sweden } \\
\hline $\begin{array}{l}\text { Which of the following energy sources } \\
\text { is not renewable? }\end{array}$ & 63.9 \\
\hline $\begin{array}{l}\text { Which of the following energy sources } \\
\text { contributes most energy to the } \\
\text { Swedish energy system? }\end{array}$ & 84.3 \\
\hline $\begin{array}{l}\text { Which of the following energy sources } \\
\text { contributes least energy to the } \\
\text { Swedish energy system? }\end{array}$ & 73.5 \\
\hline \multicolumn{2}{|l|}{ Average household usage } \\
\hline $\begin{array}{l}\text { How much electricity does an average } \\
\text { apartment/freestanding home } \\
\text { respectively use in a year? }\end{array}$ & 54.2 \\
\hline \multicolumn{2}{|l|}{ In-home energy consumption } \\
\hline $\begin{array}{l}\text { Which of the following appliances uses } \\
\text { most energy (watts) during } 1 \mathrm{~h} \text { of } \\
\text { activity? }\end{array}$ & 42.2 \\
\hline $\begin{array}{l}\text { Which of the following appliances has, } \\
\text { in an average household, the biggest } \\
\text { impact on the energy bill? }\end{array}$ & 33.7 \\
\hline
\end{tabular}

ranged from easy to difficult to capture the knowledge of both the most and the least knowledgeable respondents. Table 1 shows the percentage of correct responses (i.e. item difficulty) to each question. All knowledge questions were combined to one composite score. Cronbach's alpha of this composite was $0.666(M=4.53, S D=1.40)$. Scoring high (maximum score was seven) meant having answered most questions correctly and thus 'knowing' more.

\section{Theory-derived constructs}

Attitudes, subjective norms and perceived behaviour control On 7-point scales, we asked respondents to indicate for the given beliefs (1) if they agreed with 
the belief (thus if they held this particular belief) and (2) whether they considered it important (strength), both on 7-point scales. For attitudes, each behaviour was assessed with the common beliefs: economic benefits, environmental benefits and effects on comfort, plus the specific beliefs for some of the behaviours. Questions appeared in the following style:

- Investing in PV cells [or other behaviour] would improve my household's financial situation (strongly disagree $\longleftrightarrow \longrightarrow$ strongly agree)

- Improving my household's financial situation is ... (very unimportant $\longleftrightarrow \longrightarrow$ very important)

Questions about subjective norms followed the same rationale and structure as those for attitudes. Respondents were asked about two beliefs (opinions of peers and opinions of family, friends or neighbours, respectively), for example:

- Investing in solar energy cells [other behaviour] is something friends, family and neighbours [people with households like mine] would expect of me (strongly disagree $\longleftrightarrow \longrightarrow$ strongly agree)

- Living up to the expectations of friends, family and neighbours [people with households like mine] is for me... (very unimportant $\longleftrightarrow$ very important)

The pre-pilot also identified potential barriers for the different behaviours, of which none was shared among all four behaviours. Here, respondents thus replied to different beliefs for each behaviour, which were again similar in style to those on attitude and subjective norm, for example:

- My household does not have the economic means to invest in PV cells [other behaviour] (strongly disagree $\longleftrightarrow$ strongly agree)

- Not having the economic means to invest is... (Not at all a barrier $\longrightarrow$ a very large barrier)

Moral norms Moral norms were assessed with a single question that followed closely after the TPB constructs, asking respondents to rate their consent to the statement below, with a 7-point scale ranging from strongly disagree to strongly agree.

- I have a moral obligation to invest in PV cells [other behaviour]
Intentions to behaviour Intentions were assessed by asking respondents if they agreed with the statement below, with a 7-point scale ranging from strongly disagree to strongly agree.

- I intend to invest in PV cells [other behaviour]

Data analysis

The composite scores for attitudes, subjective norms and perceived behaviour control were all rescaled to the 1-7 item scale that questions were originally put in, to facilitate means comparisons with means on moral norms and intentions. Many variables were found to be non-normal, so statistical tests were non-parametric.

\section{Results}

Our aim in this study was to see if the described set of determinants in the "Theory-derived constructs" section had a clear and unequivocal effect on intentions towards the four energy-saving behaviours or whether differences can be found between these in terms of their determinants. To this end, we first look at the potential of general energy awareness and knowledge as determinants to energy behaviour (intentions to save or otherwise be energy 'friendly'). Thereafter, we have a closer look at the differences between the four behaviours in terms of means of intentions and the determinants: attitudes, subjective norms, PBC and moral norms (and underlying beliefs). This is a means comparison, which implies that we compare the level of strength with which respondents assessed each of these determinants. Such an analysis may not reveal whether the determinants actually co-vary with intentions to behave; in order to elucidate this, we run four ordinal logistic regression analyses in the last section to see which determinants are predictors to intentions to behave.

Knowledge and awareness

As a first step in investigating if awareness and knowledge of energy consumption affected behaviours and intentions, we looked at the correlations between these variables. If awareness (knowledge) is causally related to behavioural intent (either as a determinant or a consequence), then a correlation between these variables should exist. 
Respondents' composite scores on awareness and knowledge were related to one another, $\left(r_{\text {Spearman }}=.396\right.$, $p<0.001$ ). However, no clear correlations could be found between awareness (knowledge) and intentions to behave, except for replacing household appliances. Awareness correlated to intentions to replace household appliances $(r=.284, p=0.019)$, as did knowledge $\left(r_{s}=.260, p=0.032\right)$. All other correlations had an absolute magnitude below $r_{s}=.225$, ns.

At this point in the analysis, we concluded that awareness and knowledge (as was measured in this survey) were not likely candidate determinants for (intentions to) energy-saving behaviour, except for replacing old household appliances with new more energy-efficient ones.

\section{Intentions to behave}

Figure 1 shows the means with $95 \%$ confidence intervals for respondents' scores on intentions to perform each behaviour. A comparison of these means (as well as a visual inspection of the figure) revealed that these means are significantly different, Friedman's chi square $\chi^{2}(3)=63.556, p<0.001$, with the mean of intentions to invest in PV cells being significantly lower than the other intention means. This suggests that respondents were more motivated to perform the daily repeated behaviours (turning off apparatus on standby mode and showering less) than the one-off investment behaviour of investing in PV cells. However, intentions for replacing household appliances matched those of the quick and cheap behaviours, which reduces the likelihood of 'repeated nature' or cheapness as causes for the difference. Investing in PV cells also differs from the other behaviours in terms of initial costs, with turning off standby and showering less being 'free of pecuniary cost' altogether and replacing household items somewhere in the middle between no costs and those incurred when investing in PV cells. ${ }^{8}$ To investigate this difference in intentions further, we looked at how the ТРВ constructs and underlying beliefs differed per behaviour.

\section{Behavioural determinants and underlying beliefs}

Table 2 shows the mean of each of the TPB constructs and moral norm per behaviour, showing the motivations people have in performing each behaviour. Note that these

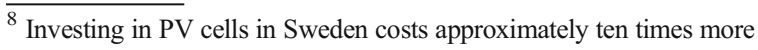
than installing an average piece of household appliance.
}

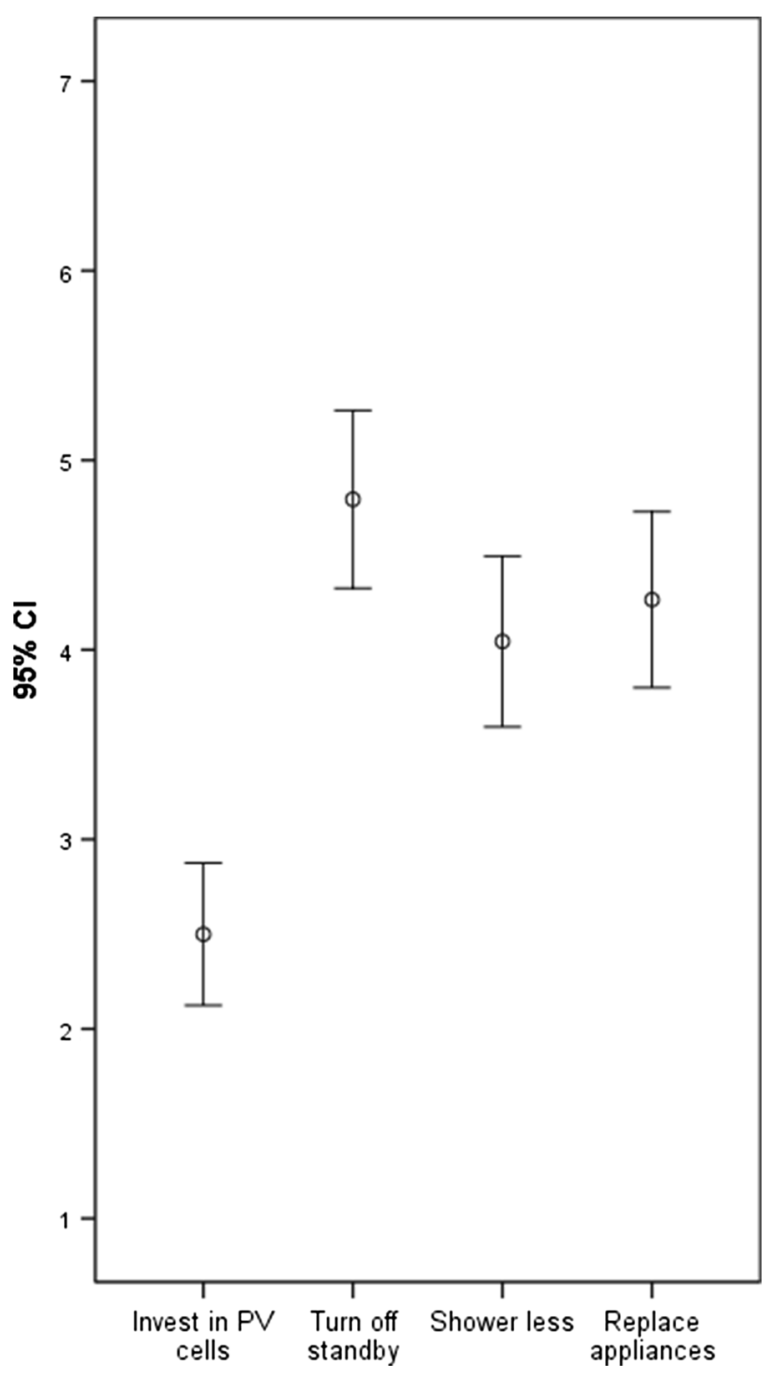

Fig. 1 Means and 95\% confidence intervals around the four intentions to behave, on a scale of 1 to $7(1=$ low intention $)$

means were of combined scores on a number of beliefs (with the exception of moral norms, which is based on one question). A brief observation on subjective norms is that it seems that no matter the behaviour, subjective norms were not a strong motivator (in people's own assessment). Indeed, as is shown later, subjective norms did not come out as a significant predictor in regressions onto intentions either. We hypothesize that since the behaviours in this survey were of a private nature (one performs them at home), the opinions of others outside the household were held to be trivial by respondents. However, we have no measure for interpreted level of privacy so we cannot support such hypothesis.

In Table 2, we can also see that the relatively 'easy and cheap' behaviours (turning off standby and 
Table 2 Means and standard deviation of determinants to behaviour

\begin{tabular}{lllllllllllll}
\hline & $\begin{array}{l}\text { Number } \\
\text { Invest in PV cells }\end{array}$ & SD & $\begin{array}{l}\text { Number } \\
\text { Shower less }\end{array}$ & Mean & SD & $\begin{array}{c}\text { Number } \\
\text { Turn off standby }\end{array}$ & Sean & $\begin{array}{c}\text { Number } \\
\text { Replace appliances }\end{array}$ \\
\hline Attitudes & 72 & 2.664 & 1.361 & 70 & 2.537 & 1.33 & 70 & 2.694 & 1.183 & 68 & 4.224 & 1.62 \\
Subjective norms & 72 & 1.15 & 1.255 & 70 & 1.12 & 1.195 & 70 & 1.366 & 1.381 & 68 & 1.081 & 1.189 \\
PBC & 72 & 2.811 & 1.484 & 70 & 1.892 & 1.524 & 70 & 2.438 & 1.207 & 68 & 2.62 & 1.101 \\
Moral norm & 72 & 2.708 & 1.682 & 70 & 4.057 & 1.887 & 70 & 4.014 & 1.96 & 68 & 3.662 & 1.645 \\
\hline
\end{tabular}

When needed, rescaled to $1-7$

showering less) have the highest average mean for moral norms (which indicates that respondents felt most responsible for these behaviours, compared to the other two behaviours). For the (often) one-off behaviour of investing in PV cells, moral norms were not as high, more on par with attitudes and PBC scores (expressed as barriers to perform the behaviour). Replacing appliances seems to take a somewhat middle ground between these extremes.

We ran Friedman tests to see if the means of each construct were significantly different between behaviours. For attitudes, we found a significant difference between the four means $\left(\chi^{2}(3)=60.43, p<0.001\right)$; post hoc Wilcoxon tests reveal that attitudes for replacing old household appliances were significantly higher than for the other behaviours. Subjective norm values differed as well, $\left(\chi^{2}(3)=14.67, p=0.002\right)$, with a difference between replacing appliances and turning off standby as the only significant post hoc difference, as did the means of PBC $\left(\chi^{2}(3)=26.09, p<0.001\right)$, with showering less being significantly less impeded by barriers than the other behaviours. Moreover, the means of moral norms differed $\left(\chi^{2}(3)=29.37, p<0.001\right)$, with moral norms for investing in PV cells being significantly less motivating than for the other three behaviours. In sum, respondents felt less morally obliged to invest in PV cells and had most positive attitudes towards replacing household appliances, in a comparison between behaviours. Although perhaps interesting on its own, there is more value to be found if we dive into the individual beliefs underlying these constructs, which we will deal with now.

\section{Behavioural beliefs}

As per TPB, beliefs differ per behaviour; thus, the beliefs underlying intentions to invest in PV cells can differ from the beliefs underlying, for example, turning off standby. In the pre-pilot, we found a set of behavioural beliefs that underlie all four behaviours (economic/financial effects, environmental benefits and effects on comfort/quality of life), and here, we compare the scores of respondents on these beliefs across behaviour. ${ }^{9}$ We do this in order to assess whether motivations (selfreported) for each of the four behaviours are similar or different. As we saw in the previous section, there seem to be differences in attitudes, PBC, and moral and subjective norms. Here, we ask the question if this difference is visible on the sublevel of beliefs and if this level can add to our understanding.

Figure 1 suggests that respondents had less intentions towards investing in PV cells than the other behaviours, and we hypothesized that this could have been due to the lack of financial incentives (direct savings that compensate for initial costs). Comparing means of behavioural beliefs revealed that the behavioural beliefs concerning 'economic benefits' were not the same across behaviours $\left(\chi^{2}(3)=34.695, p<0.001\right)$. Indeed, investing in PV cells' mean was significantly lower than the means for the other behavioural beliefs, which indicates that people believed less strongly in the financial benefits of PV cell installation. It seems that respondents did not heed the market's endorsement of PV cells as 'economically sound' decision, in that one makes good investments with large savings in the long run. In the short run, it, however, is not financially beneficial to invest in PV cells, as a large upfront investment is required, whereas no (relatively small) initial investments are needed for turning off standby modes and showering less (respectively, investing in new household appliances).

\footnotetext{
$\overline{9}$ Concerning the normative beliefs (underlying subjective norms), there was no significant difference between the two different normative belief questions, and scores were low overall. For the perceived barriers, control beliefs differed completely from one to the other behaviour that we could not compare them between behaviours.
} 
Environmental benefits concerning all four behaviours were important, and no differences in their means were found across behaviours, $\chi^{2}(3)=3.489, p=.322$. It seems that respondents assessed all these behaviours as equally important 'good' practices for the environment, which suggests they were insensitive to the magnitude of the potential effect of each behaviour; objectively, the belief valence (how positively one believes a behaviour affects the environment) and importance should be higher for investment in PV cells than turning off standby. However, we did not ask participants to directly compare the four behaviours on behalf of environmental impact, so it may be possible that they were operating with different internal meters when answering these questions.

The beliefs concerning effects on comfort were significantly different, $\chi^{2}(3)=157.52, p<0.001$ ), with these being more important for appliance replacement, compared to the other behaviours. However, questions about comfort for turning off lights and showering less were stated in terms of 'loss of comfort' and replacing household appliances in terms of 'gain in comfort' (in the case of investment in PV cells, respondents were asked to first indicate if they believed this action would result in a gain or loss of comfort). These concepts are not necessarily two opposites of the same scale, and we can therefore only compare showering less with turning off standby and investing in PV cells with replacing household appliances. From this, it follows that the belief concerning reduction of comfort did not differ between showering less and turning off standby, but that there was a significant difference between assessments of increased comfort for investing in PV cells and replacing household appliances, with the latter behaviour being held to increase comfort more than the former. This rings true, as new household appliances are, apart from being environmentally friendly, also often quicker, more effective in their task and less noisy, for instance; in total, more comfortable. PV panels, however, do not provide any comfort; they merely exist and deliver electricity.

To conclude, then, we saw that there are some differences in how behavioural beliefs are assessed across the behaviours we measured. We saw that economic beliefs were less strong for PV cell installation, despite its endorsement as a sound long-term investment. We also saw that the beliefs about environmental benefits are shared across all behaviours and are assessed as equally important. Finally, the effects on comfort (be they positive or negative) were considered important, though in the case of comfort gain, more is believed to be gained from household appliances compared to PV cells. Now, we turn to the last determinant of this study: moral norms.

\section{Moral norms}

Moral norms' means differed across behaviours $\left(\chi^{2}(3)=29.368, p<0.001\right)$, with assessments of moral responsibility being high for all three behaviours except for investing in PV cells. One possible explanation is that respondents, of whom some lived in rental apartments or condominiums, felt that they had no possibility to invest in PV cells, even if they wanted to, and thus consequently did not feel a moral obligation to do this behaviour as much as the performance of the other behaviours. Another explanation could be that there is no direct monetary incentive to invest in PV cells (no immediate gains in electricity savings to be made), and for respondents who had decided for themselves that they are not 'the people' who invest in such things, the feeling of moral obligation is gone. Earlier, we saw that indeed, the belief concerning economic benefits was less for investment in PV cells compared to the other behaviours. We delve deeper into the possible implications of these results in the discussion.

For now, we conclude that respondents were less motivated by economic investments and moral concerns about investment in PV panels, whereas for the replacement of household appliances they were motivated by economic incentives and improved comfort. For the more mundane everyday behaviours of turning off standby and showering less, economy, environment and moral concerns were all motivating, while the decreased comfort speaks against performing the behaviours.

Up to this point, we have merely looked at the means of responses, which is a rough indication of how important people consider several potential motivating factors for their behaviour. However, what people think is important may not necessarily resonate with what guides their behaviour. In order to shed light on this, we also analysed which constructs co-varied with intentions to behave (and self-reported behaviour). When constructs co-vary with intention (behaviour), regardless of how high the mean is, we can carefully suggest it may be a determinant to intention to act. We explore this next in four regressions. 
Regression analyses and barriers

With four ordinal logistic regression models (one for each behavioural intent), we investigated the degree to which the constructs, attitudes, subjective norms, perceived behaviour control and moral norms, predicted the stated intention to perform the behaviours. We regressed these determinants (composite belief scores forming variables for attitudes, subjective norms and $\mathrm{PBC}$ ) onto its specific behaviour intention measure. For the replacing of household appliances, we also incorporated awareness and knowledge as determinants (see the "Knowledge and awareness" section).

The regressions (Table 3) showed that $\mathrm{PBC}$ and moral norms were strong predictors to investing in PV cells, with attitudes gaining only a marginally significant contribution. The large influence of PBC (which

Table 3 Ordinal logistic regressions of behaviour determinants onto intentions to perform to the four behaviours

\begin{tabular}{|c|c|c|c|c|}
\hline & Df. & $\begin{array}{l}\text { Logit regression } \\
\text { coef. }\end{array}$ & $\begin{array}{l}\text { Wald } \\
\text { stat. }\end{array}$ & $p$ \\
\hline \multicolumn{5}{|c|}{ Invest in PV cells } \\
\hline Attitudes & 1 & 0.374 & 3.637 & 0.057 \\
\hline $\begin{array}{l}\text { Subjective } \\
\text { norms }\end{array}$ & 1 & 0.023 & 0.011 & 0.916 \\
\hline PBC & 1 & -0.749 & 14.405 & 0.000 \\
\hline Moral norm & 1 & 0.672 & 12.909 & 0.000 \\
\hline \multicolumn{5}{|l|}{ Turn off standby } \\
\hline Attitudes & 1 & 1.193 & 22.323 & 0.000 \\
\hline $\begin{array}{c}\text { Subjective } \\
\text { norms }\end{array}$ & 1 & -0.082 & 0.192 & 0.661 \\
\hline PBC & 1 & -0.356 & 3.017 & 0.082 \\
\hline Moral norm & 1 & 0.916 & 30.774 & 0.000 \\
\hline \multicolumn{5}{|l|}{ Shower less } \\
\hline Attitudes & 1 & 0.736 & 12.142 & 0.000 \\
\hline $\begin{array}{l}\text { Subjective } \\
\text { norms }\end{array}$ & 1 & 0.411 & 2.670 & 0.102 \\
\hline $\mathrm{PBC}$ & 1 & -0.041 & 0.068 & 0.795 \\
\hline Moral norm & 1 & 0.698 & 17.092 & 0.000 \\
\hline \multicolumn{5}{|c|}{ Replace appliances } \\
\hline Awareness & 1 & 0.085 & 0.174 & 0.676 \\
\hline Knowledge & 1 & 0.177 & 0.891 & 0.345 \\
\hline Attitudes & 1 & 0.552 & 12.442 & 0.000 \\
\hline $\begin{array}{l}\text { Subjective } \\
\text { norms }\end{array}$ & 1 & 0.039 & 0.033 & 0.855 \\
\hline $\mathrm{PBC}$ & 1 & -0.119 & 0.271 & 0.602 \\
\hline Moral norm & 1 & 0.400 & 6.522 & 0.011 \\
\hline
\end{tabular}

are to be understood as barriers) is in sync with the lower mean of intentions to invest in PV cells, compared to the other behavioural intentions. The other three behaviours indeed exhibited a different pattern, where attitudes and moral norms were the significant predictors and PBC was not (or only marginally, in case of turning off apparatus from standby modes).

In the case of investing in PV cells, barriers (and accompanying means of these assessments) were not having the economic means to perform the initial investment $(M=21.63, S D=15.375)$, having no power over the decision to invest/install PV cells $(M=18.73$, $S D=16.087)$ and having little or no knowledge on how to initiate/perform such an investment $(M=18.681$, $S D=13.765) .{ }^{10}$ For the other behaviours, forgetting was the highest barrier for turning off standby $(M=18.57, S D=15.050)$, with having no apparatus that has a standby mode being assessed lower $(M=15.56, S D=12.236)$. Not being able to influence other household members' showering time was considered a comparably small barrier for showering less $(M=13.24, S D=10.668)$. For replacing household appliances, a similar argument to investing in PV cells, not having the financial capital to make the investment, was considered a barrier $(M=18.750, S D=13.179)$ but even more so was the control belief: already having replaced all old household appliances $(M=24.79$, $S D=13.394)$, with having no control over the decision to invest in appliances being comparably unimportant $(M=11.47, S D=11.757))$.

In conclusion, first, depending on the type of behaviour, either attitudes or PBC seems to contribute to intentions to perform the behaviour. For behaviours where initial economic investment is warranted and only delayed gains in the future are to be expected (investing in PV cells), barriers were a stronger predictor to intent than attitudes (though note that in the regression for PV cell, intention attitudes are still marginally significant). For slightly less 'expensive' investments such as replacing household appliances and easy behaviours such as showering less, attitudes are an important predictor; barriers are not. The marginal significance of PBC in the turning off standby behaviour is an oddity, which was expected to follow a pattern like showering less. However, the PBC construct consisted of qualitatively

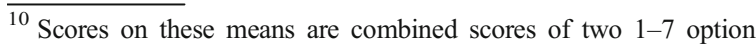
scales, assessing belief valence and belief importance (see the "Procedure and measurements" section).
} 
completely different control beliefs, which makes this result difficult to interpret. A second conclusion is that moral norms are a strong motivator for intentions to perform any of these energy behaviours, and thirdly, next to moral norms, subjective norms seem to have little importance in the assessed energy behaviours. The latter observation is in sync with earlier reviews, which underline that subjective norms are often bereft of direct effects on intention after being combined with the effects of attitude and PBC (Ajzen 1991; Armitage and Conner 2001; Bamberg \& Möser 2007; but see Nolan et al. 2008, for a counter-example).

\section{Discussion and conclusion}

\section{Discussion of findings}

One aim of this article was to investigate whether a certain set of behavioural determinants consistently motivated people and predicted their energy behaviours across different kinds of behaviour. The set of potential determinants originated from previous literature on energy and environmental behaviour, social psychology and a pre-pilot study. These were awareness and knowledge of energy consumption, attitudes (economical, environmental and comfort effects), subjective norms, perceived behaviour control and moral norms.

We found no correlations between awareness (or knowledge) on one hand and intentions to behave on the other, except for awareness and intentions to replace household appliances. In an ordinal logistic regression analysis, awareness did not predict behavioural intent either, meaning that this study gives little basis to conclude that awareness or knowledge of energy consumption is a determinant to energy behaviour. Of the other determinants, we found that moral norms are a particularly persuasive motivator, with high predictive power for all behaviours and high means in assessments of its strength, that is, how strongly they felt morally responsible to perform a behaviour. There seemed to be some difference between the behaviours in terms of which determinants were most predictive, though in general, attitudes were a good second motivator to moral norms, and in case of initially expensive behaviours (such as investing in PV cells), perceived barriers were predictive to intentions as well. One note we would like to make, before proceeding with a more detailed discussion of the results, is that the sample size with which this study was performed was rather small, which means that our results and conclusions should be considered with care. We urge the reader to see the exploratory merit in this study without interpreting the results as proven facts. Below, we discuss the findings more in depth, starting with a word or two about awareness and knowledge.

\section{Awareness}

The results of this study show no evidence for awareness as a determinant to intentions to act or as potential mechanism for spillover effects. Awareness correlated to only one intention (to replace household appliances) and did not even predict this in a regression analysis. There are several possible explanations for this, the first being the obvious one: our measure did not capture 'true awareness of one's own energy consumption'. This is indeed a possibility. However, given that the variable used was a compound score of four different (and correlating, yet not completely overlapping) items, which had a decent range across the sample population, we believe that it must have captured some aspect of awareness and other explanations should thus at least be considered.

An alternative explanation is that awareness of one's own energy consumption is not the defining awareness that induces (intentions to) behaviour. Perhaps, awareness of environmental problems (as was suggested in Gärling et al. 2003) or awareness of being aware of the consequences of one's own behaviour, rather than being aware of the behaviour itself (Abrahamse and Steg 2009), should be considered. Although this latter conception is close to the one we measured, there is a nuanced difference. Awareness of consequences of one's behaviour depends on which behaviour one has in mind, whereas awareness of energy consumption in general is not. Awareness of consequences of one's particular behaviour is considered part of the norm activation model, as a precedent of moral norms (Abrahamse and Steg 2009), and future research should focus on how this type of awareness could contribute further to explaining intentions. Suffice to say now that, if awareness of consequences of one's behaviour is indeed a precursor of moral norms, then our results do indicate an effect of this type of awareness (though for clarity, we prefer to stick to the term moral norms, or sense of moral responsibility to perform this or that behaviour). 
A third explanation for the lack of effects of awareness (and knowledge) is more dramatic in nature and possibly harder to swallow, and for obvious reasons, this single survey study cannot possibly be held as conclusive evidence for such a conclusion. It deserves mentioning nonetheless: the possibility that there is no direct (causal) link from awareness towards behaviour. A classical view in psychology, and much of our common sense thinking for that matter, is that behavioural determinants, or motivators, induce behaviour, and not the other way around. Thus, if one invests in PV cells, it is because one is aware of her/his energy consumption, knowledgeable about energy and has positive attitudes (for example). However, it is possible that processes flow in the other direction; investing in PV cells changes one's awareness, knowledge, attitudes, et cetera (Liska 1984). If one (for any reason) decides to invest in solar panels, ${ }^{11}$ motivation, awareness, knowledge and other 'determinants' may grow after this event, rather than before. If other behaviour then emerges from these changed 'determinants', we are talking about spillover effects (for example Thøgersen and Ölander 2003; Truelove et al. 2014). If we want to establish such mechanisms, however, we would need before-after (and between-group) field experiments (Truelove et al. 2014). Based on this primary study, we can only speculate.

One important suggestion, then, is that numerous interventions aimed to increase our awareness of environmental (energy) problems could be missing the mark (or in any rate may not be focused on the most important determinants to behaviour). Of course, prior studies did find effects of awareness (see Delmas et al. 2013 for an overview) but others did not (for example, Brounen et al. 2013), suggesting at least the need for modest and careful use of awareness campaigns as a magic bullet for behaviour change.

\section{Knowledge}

Much that has been said about awareness in the previous paragraphs also covers the issues with knowledge. We reiterate that one possible explanation for lack of correlations could lie in a faulty way of measuring this construct. We would like to add at this point that given the multitude of definitions of awareness (see previous section), as well as the broad range of what we can

\footnotetext{
${ }^{11}$ In fact, this is not a strange scenario; some Swedes who live in condominiums have found themselves in 'possession' of solar panels on their apartment building's roof.
}

consider 'knowledge', it becomes difficult to distinguish these two terms from one another. In future surveys, we therefore suggest that knowledge/awareness rather be divided into different categories (e.g. knowing one's behaviour's environmental impacts, being aware of one's energy consumption and being aware of the environment as an important source of life).

\section{PV cell investment, the odd one out}

The regressions in Table 3 and the earlier means analyses show a different picture for PV cell investment than the other behaviours, which seems to go against this study's aim of finding a set of determinants that consistently predicts behavioural intent. This discrepancy begs for an explanation. Why are the means of intention and moral norm for PV cell investment lower than for the other behaviours, and why is the means for beliefs in economic benefits low too, while those endorsing PV cells in the market continuously emphasize the financial gains on the long run (at least in Sweden)? We discuss two potential explanations.

A first explanation could be the lack of opportunity that more than half of the respondents had in investing in PV cells. Quite some respondents lived in condominiums or rental apartments, and thus had little to no say in whether or not to get PV cells, and potentially not the financial means either. Expectably, scores on the perceived barrier of having no opportunity to install PV cells differed significantly between the groups of villa owners $(N=18, M d n=6.5)$ and all others $(N=54$, $\operatorname{Mdn}=16$, scale from 1 to $49, Z(72)=1.50$, $p=0.023){ }^{12}$ As such, non-villa owners may have felt the questions on moral obligation and intention to be irrelevant, which would explain higher scores (higher scores indicate an increased perception of a specific barrier). Given this potential confound, we compared means on the moral norm scores between villa and nonvilla owners, but this did not reveal a significant difference, nor was there a difference between these groups' assessment of the economic benefits of installing PV cells. This is noteworthy, since there was a marginally significant difference in their self-reported household income $(Z=1.3, p=0.069, M d n$ (villas) $=60.000$ SEK, $M d n$ (non-villas) $=47.500$ SEK), which would indicate that villa owners would have more financial

\footnotetext{
${ }^{12}$ Due to the low sample size in one of the groups, we used a Kolmogorov-Smirnov independent samples test.
} 
margin for such investments. It seems that a potentially higher household income and power over one's own roof did not affect the assessments of moral responsibility or beliefs about economic benefits.

A second explanation for the lower scores in intentions, moral norms and economic benefits perceived from investing in PV cells could come from the decision mode a person uses when thinking of a behaviour (Truelove et al. 2014). A decision mode can be calculation-based, in which case analytic processing of pros and cons is involved in making a reasoned choice. It can alternatively be affect-based, which are more laden with emotions and less elaborated. Then, there are rule- or role-based decisions, which are more based on people's perspectives on what one ought to do (the social rule of conduct) (Truelove et al. 2014). Weber et al. (2005) suggest that there is a strong effect of the domain of a decision on the decision mode that they use.

In the review of Truelove and colleagues, decision modes are related to spillover effects (ibid), but here, we consider that they may also have had an influence on the effects from determinants to intentions to behave. In other words, we suggest that when reading about the behaviour 'PV cell investment', people started thinking in dollar signs (Swedish kronor signs in our case, a decidedly calculation-based mode of thinking) and concluded that moral obligations, a rather emotional affair, had nothing to do with it. When they were thinking of the relatively easy behaviours like turning off standby, they were possibly more inclined to think in terms of simple 'ought' and 'ought nots', a 'rule-based mode of decision', or in terms of emotions of regret and guilt (affect-based decision modes). Indeed, guilt and regret have in the past been linked to pro-environmental behaviour (Chan and Bishop 2013; Kaiser et al. 2008) and are often linked to negative spillover effects called 'moral cleansing', where regret or guilt for a past immoral behaviour leads to a future moral act (BrañasGarza et al. 2013; Gollwitzer and Melzer 2012; Sachdeva et al. 2009; Zhong and Liljenquist 2006). Although it was not the purpose of this study to investigate moral regulation effects or decision modes, we do believe that these could have been a crucial aspect of why the determinants under investigation showed a different pattern across behaviours. As such, the nature of the decision mode that is being induced may in fact be a cue to the occurrence and direction of spillover effects, rather than the direct involvement of raised awareness. In other words, when a behaviour elicits a calculation- based mode of thinking, different determinants are in play than when an affect-based or rule-based mode of decision-making is involved. Future studies could test if this distinction is indeed true for more than the behaviours tested in this study.

\section{Limitations of the study}

There are some initial limitations to the study that warrant mentioning. First, using surveys to assess human behaviour or constructs like attitudes has its pitfalls. Behaviour is difficult to assess objectively via self-reports, as self-reports tend to be overestimations of reality or lack correlation with real behaviour completely (Chao and Lam 2011; Corral-Verdugo 1997). Latent variables like attitudes can be equally tricky to capture in surveys, particularly if these are partly outside of our consciousness. As an example, research into implicit pro-environmental attitudes (attitudes outside of our consciousness) showed that these can affect how much attention we pay to visuals of climate change (Beattie and Mcguire 2012); suffice to say that such implicit nonreportable attitudes can also influence behaviour in other situations. It is for this reason that we kept the main analyses in this survey limited to the self-reportable area, which implies that we focused on reportable attitudes, norms, perceived barriers and intentions.

A second issue is that a 'humane' survey must be limited in size, as respondents have limited attention spans and cannot be asked to sit and answer questions all day long (at least not for one cinema ticket). Consequently, we cannot ask them about a hundred different behaviours or measure an equal amount of behaviour determinants. This limitation is seen in the fact that we did not incorporate all possible constructs that have been used in the past to explain behaviour, e.g. habits or physical constraints (Steg and Vlek 2009). We believe, however, that the TPB combined with the NAT has enough literature supporting its use to warrant the adoption of their constructs.

A caveat in the design of the survey needs to be mentioned too: the questions on moral norms and intentions for each behaviour were asked consecutively. It may thus be the case that the strong correlation between the two should be attributed (partly) to this nearness in time of answering. Note however that although this fact may to some extent have inflated the magnitude of the correlation between moral norm and intention, the nearness of the questions does not affect the conclusions 
concerning the different levels of assessment of moral norms across the four behaviours (as questions for all behaviours were in the same shape, size and sequence). However, a future survey design would do well to vary or separate the vicinity of these two questions as to prevent such an influence to occur altogether.

Conclusion: energy consciousness - does it have

a common cause or is it a lost cause?

This study aimed to investigate the role of a specific set of determinants in four different energy behaviours: investing in solar panels, turning off appliances that are on standby, reducing the time spent showering and replacing old household appliances with new energyefficient ones, to see if there is consistency in that certain determinants are involved in all behaviours or not. In other words, is there a consistent package of determinants to energy behaviour? Our tentative conclusion is positive. Although we did not find a uniform set of determinants that always predict every type of energy behaviour, we did uncover a set of motivators that are often related to these kinds of behaviours. We tentatively suggest that one can indeed express energy behaviour in a set of determinants consisting of attitudes towards the behaviour, their perceived behaviour control (in cases where behaviours are either initially costly or difficult to perform, or tentatively where calculation-based modes of decision are involved) and moral norms. We also suggest that subjective norms ought to not yet be thrown out of the equation. Although we did not find any relevance to it in this study, this may be attributable to the private nature of most of these behaviours (although investing in PV cells is a borderline case, with the panels themselves being visible to outsiders). More public proenvironmental behaviour (like bicycling to work) may indeed be more affected by subjective norms. Also, we do not want to exclude the possibility that there is a role to play for awareness and knowledge, but we do underline that these constructs are not easily captured and probably entwined with other constructs; whatever awareness of energy is, it is not simply knowing one's own energy use, nor is knowledge about facts in a simple way adding to our pro-environmental activity.

\section{Compliance with ethical standards}

Conflict of interest The authors declare that they have no conflict of interest.
Open Access This article is distributed under the terms of the Creative Commons Attribution 4.0 International License (http:// creativecommons.org/licenses/by/4.0/), which permits unrestricted use, distribution, and reproduction in any medium, provided you give appropriate credit to the original author(s) and the source, provide a link to the Creative Commons license, and indicate if changes were made.

\section{References}

Abrahamse, W., \& Steg, L. (2009). How do socio-demographic and psychological factors relate to households' direct and indirect energy use and savings? Journal of Economic Psychology, 30, 711-720. doi:10.1016/j.joep.2009.05.006.

Abrahamse, W., Steg, L., Vlek, C., \& Rothengatter, T. (2007). The effect of tailored information, goal setting, and tailored feedback on household energy use, energy-related behaviors, and behavioral antecedents. Journal of Environmental Psychology, 27, 265-276. doi:10.1016/j.jenvp.2007.08.002.

Ajzen, I. (1991). The theory of planned behavior. Organizational Behavior and Human Decision Processes, 50(2), 179-211. doi: 10.1016/0749-5978(91)90020-T

Armitage, C. J., \& Conner, M. (2001). Efficacy of the theory of planned behaviour: a meta-analytic review. The British Journal of Social Psychology, 40(Pt 4), 471-499 Retrieved from http://www.ncbi.nlm.nih.gov/pubmed/11795063.

Bamberg, S., \& Schmidt, P. (2003). Incentives, morality, or habit?: predicting students' car use for university routes with the models of Ajzen, Schwartz, and Triandis. Environment \& Behavior, 35(2), 264-285. doi:10.1177/0013916502250134.

Bamberg, S., \& Möser, G. (2007). Twenty years after Hines, Hungerford, and Tomera: a new meta-analysis of psychosocial determinants of pro-environmental behaviour. Journal of Environmental Psychology, 27(1), 14-25. doi: 10.1016/j. jenvp.2006.12.002 .

Beattie, G., \& Mcguire, L. (2012). See no evil? Only implicit attitudes predict unconscious eye movements towards images of climate change*. Semiotica, 192, 315-339. doi:10.1515 /sem-2012-0066.

Brañas-Garza, P., Bucheli, M., Espinosa, M. P., \& García-Muñoz, T. (2013). Moral cleansing and moral licenses: experimental evidence. Economics and Philosophy, 29, 199-212. doi:10.1017/S0266267113000199.

Brounen, D., Kok, N., \& Quigley, J. M. (2013). Energy literacy, awareness, and conservation behavior of residential households. Energy Economics, 38, 42-50. doi:10.1016/j. eneco.2013.02.008.

Chan, L., \& Bishop, B. (2013). A moral basis for recycling: extending the theory of planned behaviour. Journal of Environmental Psychology, 36, 96-102. doi:10.1016/j. jenvp.2013.07.010.

Chao, Y.-L., \& Lam, S.-P. (2011). Measuring responsible environmental behavior: self-reported and other-reported measures and their differences in testing a behavioral model. Environment and Behavior, 43(1), 53-71. doi:10.1177 /0013916509350849. 
Corral-Verdugo, V. (1997). Dual "realities" of conservation behavior: self-reports vs observations of re-use and recycling behavior. Journal of Environmental Psychology, 17(2), 135145. doi:10.1006/jevp.1997.0048.

Delmas, M. A., Fischlein, M., \& Asensio, O. I. (2013). Information strategies and energy conservation behavior: a meta-analysis of experimental studies from 1975 to 2012 . Energy Policy, 61, 729-739. doi:10.1016/j. enpol.2013.05.109.

DeWaters, J. E., \& Powers, S. E. (2011). Energy literacy of secondary students in New York State (USA): a measure of knowledge, affect, and behavior. Energy Policy, 39(3), 16991710. doi:10.1016/j.enpol.2010.12.049.

Dietz, T., Gardner, G. T., Gilligan, J., Stern, P. C., \& Vandenbergh, M. P. (2009). Household actions can provide a behavioral wedge to rapidly reduce US carbon emissions. Proceedings of the National Academy of Sciences of the United States of America, 106(44), 18452-18456. doi:10.1073 /pnas.0908738106.

Dincer, I. (2000). Renewable energy and sustainable development: a crucial review. Renewable and Sustainable Energy Reviews, 4(2), 157-175. doi:10.1016/S1364-0321(99 )00011-8.

Eurostat (2016). Consumption of energy - statistics explained. Retrieved November 24, 2016, from http://ec.europa. eu/eurostat/statistics-explained/index.php/Consumption_of energy.

Gärling, T., Fujii, S., Gärling, A., \& Jakobsson, C. (2003). Moderating effects of social value orientation on determinants of proenvironmental behavior intention. Journal of Environmental Psychology, 23(1), 1-9. doi:10.1016/S02724944(02)00081-6.

Gollwitzer, M., \& Melzer, A. (2012). Macbeth and the joystick: evidence for moral cleansing after playing a violent video game. Journal of Experimental Social Psychology, 48, 13561360. doi:10.1016/j.jesp.2012.07.001.

Gram-Hanssen, K. (2010). Residential heat comfort practices: understanding users. Building Research \& Information, 38(2), 175-186. doi:10.1080/09613210903541527.

Harland, P., Staats, H., \& Wilke, H. A. M. (1999). Explaining proenvironmental intention and behavior by personal norms and the theory of planned behavior. Journal of Applied Social Psychology, 29(12), 2505-2528. doi:10.1111/j.15591816.1999.tb00123.x.

Hirschnitz-Garbers, M., Tan, A. R., Gradmann, A., \& Srebotnjak, T. (2016). Key drivers for unsustainable resource use - categories, effects and policy pointers. Journal of Cleaner Production, 132, 13-31. doi:10.1016/j.jclepro.2015.02.038.

Kaiser, F. G., Hubner, G., \& Bogner, F. X. (2005). Contrasting the theory of planned behavior with the value-belief-norm model in explaining conservation behavior. Journal of Applied Social Psychology, 35(10), 2150-2170. doi:10.1111/j.15591816.2005.tb02213.x.

Kaiser, F. G., Schultz, P. W., Berenguer, J., Corral-Verdugo, V., \& Tankha, G. (2008). Extending planned environmentalism. European Psychologist, 13(4), 288-297. doi:10.1027/10169040.13.4.288.

Kallbekken, S., Sælen, H., \& Hermansen, E. A. T. (2013). Bridging the energy efficiency gap: a field experiment on lifetime energy costs and household appliances. Journal of
Consumer Policy, 36(1), 1-16. doi:10.1007/s10603-0129211-z.

Klöckner, C. A. (2013a). A comprehensive model of the psychology of environmental behaviour - a meta-analysis. Global Environmental Change, 23(5), 1028-1038. doi: 10.1016/j. gloenvcha.2013.05.014 .

Klöckner, C.A. (2013b). How powerful are moral motives in environmental protection? An integrated model framework. In: Heinrichs, K., Oser, F., Lovat, T. (Eds.), Handbook of Moral Motivation. Theories, Models and Applications. Sense Publishers, Rotterdam, NL.

Klöckner, C. A., \& Blöbaum, A. (2010). A comprehensive action determination model: toward a broader understanding of ecological behaviour using the example of travel mode choice. Journal of Environmental Psychology, 30(4), 574 586. doi:10.1016/j.jenvp.2010.03.001.

Kollmuss, A., \& Agyeman, J. (2002). Mind the gap: why do people act environmentally and what are the barriers to proenvironmental behavior? Environmental Education Research, 8(3), 239-260. doi:10.1080/13504620220145401.

Kormos, C., \& Gifford, R. (2014). The validity of self-report measures of proenvironmental behavior: a meta-analytic review. Journal of Environmental Psychology, 40, 359-371. doi:10.1016/j.jenvp.2014.09.003.

Liska, A. E. (1984). A critical examination of the causal structure of the Fishbein/Ajzen attitude-behavior model. Social Psychology Quarterly, 47(1), 61-74. doi:10.2307/3033889.

Lopes, M. A. R., Antunes, C. H., \& Martins, N. (2012). Energy behaviours as promoters of energy efficiency: a 21st century review. Renewable and Sustainable Energy Reviews, 16(6), 4095-4104. doi:10.1016/j.rser.2012.03.034.

Manstead, A. S. R. (2000). The role of moral norm in the attitudebehavior relation. In Attitudes behavior and social context the role of norms and group membership (pp. 11-30). https://doi. org/ehs HM132 B48 2000.

Nair, G., Gustavsson, L., \& Mahapatra, K. (2010). Factors influencing energy efficiency investments in existing Swedish residential buildings. Energy Policy, 38(6), 29562963. doi:10.1016/j.enpol.2010.01.033.

Nolan, J. M., Schultz, P. W., Cialdini, R. B., Goldstein, N. J., \& Griskevicius, V. (2008). Normative social influence is underdetected. Personality \& Social Psychology Bulletin, 34(7), 913-923. doi:10.1177/0146167208316691.

Pichert, D., \& Katsikopoulos, K. V. (2008). Green defaults: information presentation and pro-environmental behaviour. Journal of Environmental Psychology, 28(1), 63-73. doi:10.1016/j.jenvp.2007.09.004.

Reynolds, T. W., Bostrom, A., Read, D., \& Morgan, M. G. (2010). Now what do people know about global climate change? Survey studies of educated laypeople. Risk Analysis, 30(10), 1520-1538. doi:10.1111/j.1539-6924.2010.01448.x.

Sachdeva, S., Iliev, R., \& Medin, D. L. (2009). Sinning saints and saintly sinners: the paradox of moral self-regulation: research article. Psychological Science, 20(4), 523-528. doi:10.1111 j.1467-9280.2009.02326.x.

SCB, S. centralbyrån (2016). Befolkningens utbildning. Retrieved October 27, 2016, from http://www.scb.se/sv_/Hittastatistik/Statistik-efter-amne/Utbildning-ochforskning/Befolkningens-utbildning/Befolkningensutbildning/\#c_undefined. 
Schultz, P. W., Nolan, J. M., Cialdini, R. B., Goldstein, N. J., \& Griskevicius, V. (2007). The constructive, destructive, and reconstructive power of social norms: research article. Psychological Science, 18(5), 429-434. doi:10.1111/j.14679280.2007.01917.x.

Schwartz, S. H. (1977). Normative influences on altruism. Advances in Experimental Social Psychology, 10, 221-279. doi:10.1016/S0065-2601(08)60358-5.

Shove, E. (2010). Beyond the ABC: climate change policy and theories of social change. Environment and Planning A, 42(6), 1273-1285. doi:10.1068/a42282.

Sovacool, B. K. (2009). The cultural barriers to renewable energy and energy efficiency in the United States. Technology in Society, 31(4), 365-373. doi:10.1016/j.techsoc.2009.10.009.

Steg, L., \& Vlek, C. (2009). Encouraging pro-environmental behaviour: an integrative review and research agenda. Journal of Environmental Psychology, 29(3), 309-317. doi:10.1016/j.jenvp.2008.10.004.

Thøgersen, J., \& Ölander, F. (2003). Spillover of environmentfriendly consumer behaviour. Journal of Environmental Psychology, 23(3), 225-236. doi:10.1016/S0272-4944(03 )00018-5.

Tiefenbeck, V., Staake, T., Roth, K., \& Sachs, O. (2013). For better or for worse? Empirical evidence of moral licensing in a behavioral energy conservation campaign. Energy Policy, 57, 160-171. doi:10.1016/j.enpol.2013.01.021.

Truelove, H. B., Carrico, A. R., Weber, E. U., Raimi, K. T., \& Vandenbergh, M. P. (2014). Positive and negative spillover of pro-environmental behavior: an integrative review and theoretical framework. Global Environmental Change, 29, 127138. doi:10.1016/j.gloenvcha.2014.09.004.

Wall, R., Devine-Wright, P., \& Mill, G. A. (2007). Comparing and combining theories to explain proenvironmental intentions: the case of commuting-mode choice. Environment and Behavior, 39(6), 731-753. doi:10.1177/0013916506294594.

Wallenborn, G., \& Wilhite, H. (2014). Rethinking embodied knowledge and household consumption. Energy Research and Social Science, 1, 56-64. doi:10.1016/j. erss.2014.03.009.

Weber, E. U., Ames, D. R., \& Blais, A.-R. (2005). "How do I choose thee? Let me count the ways": a textual analysis of similarities and differences in modes of decisionmaking in China and the United States. Management and Organization Review, 1(1), 87-118. doi:10.1111 j.1740-8784.2004.00005.x.

Zhong, C.-B. C.-B., \& Liljenquist, K. (2006). Washing away your sins: threatened morality and physical cleansing. Science, 313(5792), 1451-1452. doi:10.1126/science.1130726. 